\title{
GABRIEL GARCÍA MÁRQUEZ Y LA ÉTICA EN CIEN AÑOS DE SOLEDAD - II
}

\author{
Luis Carlos Herrera Molina, S. J.* \\ doi:10.11144/Javeriana.uph32-65.ggmc
}

\begin{abstract}
RESUMEN
La esta segunda y última parte de esta colaboración, expone y justifica que Cien años de soledad condensa un planteamiento ético - de acento veterotestamentario: pecado/castigo-, acerca de las costumbres, hábitos, creencias y valoraciones propias del obrar humano en la historia de Macondo. Esta novela es un símbolo de la moral viviente no solo en la región sino en el mundo entero. Un matriarcado ético corre -en soledad desgraciada-, como un magma de miedos y premoniciones, conciencia moral rigorista y relajamiento escandaloso; homicidios, incestos y lujuria; explotación laboral, injusticia, dependencia y despilfarro, la irreversible pendiente de no poder contar ya con una segunda oportunidad sobre la tierra.
\end{abstract}

Palabras clave: Cien años de soledad; Gabriel García Márquez; ética; mal; matriarcado ético

\footnotetext{
Pontificia Universidad Javeriana, Bogotá, Colombia.

Correo electrónico: luis.herrera@javeriana.edu.co

El presente artículo es la reimpresión, autorizada por el autor, de los capítulos XIII y XIV del libro: Herrera Molina S.J., L.C. (2005). Profetas de nuestro tiempo. Neiva: Gobernación del departamento del Huila. Para esta publicación se han hecho ajustes editoriales.

Para citar este artículo: Herrera Molina S.J., L.C. (2015). Gabriel García Márquez y la ética en Cien años de soledad - II. Universitas Philosophica, 32(65), pp. 245-274 ISSN 0120-5323, ISSN en línea: 2346-2426,doi: 10.11144/ Javeriana.uph32-65.ggmc
} 


\title{
GABRIEL GARCÍA MÁRQUEZ AND ETHICS IN ONE HUNDRED YEARS OF SOLITUDE - II
}

\author{
Luis Carlos Herrera Molina S. J.
}

\begin{abstract}
The second and final part of this collaboration shows and justifies how One Hundred Years of Solitude condenses an ethical approach -with vetero testamentary accent: sin/punishment- about the customs, habits, beliefs and own assessments of human action in the history of Macondo. This novel is a symbol of moral living not only in the region but in the whole world. An ethical matriarchy runs -in wretched solitude- as magma of fears and premonitions, stickler conscience and scandalous relaxation; murder, incest and lust; labor exploitation, injustice, dependency and extravagance, the irreversible slope of no longer have a second opportunity on earth.

Key words: One Hundred Years of Solitude; Gabriel García Márquez; ethics; evil; ethical matriarchy
\end{abstract}




\section{Acercamiento a un planteamiento ético. Factores determinantes}

Al abordar El tema Central de la investigación sobre Cien años de soledad y al aplicar la ética a los comportamientos de Macondo, descubrimos cómo la ética y la estética son disciplinas íntimamente ligadas entre sí y, también, cómo esta relación aparece en el transcurso de la obra. No se trata solo de afinidad en el sonido de las palabras, (ética = estética), sino de que ambas están unidas en un sólido principio: la ética es un elemento esencial en la vida de los personajes imaginarios, sea como constitutivo necesario de su humanidad o como símbolo que se proyecta hacia la realidad del hombre histórico y la normatividad que rige su comportamiento. Para que un hombre sea libre, para que sea perfecto, esto es, verdaderamente humano, requiere de la ética como un desafío de su realización. Los personajes inhumanos no pueden constituir un mundo verdadero y estético.

La ética ${ }^{1}$, como elemento constitutivo de los personajes de Cien años de soledad, se percibe fácilmente al recorrer el texto. Antes de la fundación de Macondo, la pareja primordial había emprendido un éxodo, urgida por dos cargos de conciencia: la unión incestuosa y el homicidio, que reñían con sus principios éticos. José Arcadio y Úrsula "estaban ligados hasta la muerte por un vínculo más sólido que el amor: un común remordimiento de conciencia ${ }^{2}$ (...) Tenían el temor de que aquellos saludables cabos de dos razas secularmente entrecruzadas,

1 "Ethos es un término griego que significa comportamiento individual y comunitario y que da origen a la palabra ética. La ciencia ética es la reflexión sistemática sobre el valor del comportamiento humano, su razonabilidad, su estructura y fundamentos últimos" (Novoa, 2000, p. 471). Ética es la ciencia de los comportamientos humanos en relación con el bien y el mal. .

En Fries (1931, citado por Guariglia, 1992, p. 55) encontramos reformulada: "la ley moral normativa", pues afirma que "la razón tiene valor infinito y a ella le asignamos la idea de dignidad: porque solo la dignidad de la persona la convierte en fin absoluto y solo así, puede elevarse a ley universal".

2 "La conciencia es aquella íntima claridad que tiene la persona de deberse como don y tarea (...) de donde emerge la percepción de una responsabilidad, se refiere al hombre en toda su profundidad y su totalidad, y a sus expresiones y realizaciones práxicas concretas, es decir, a su verdadera y plena autorrealización" (Fuchs, 1986, citado por Novoa S.J., 1995, p. 20).

Según el Vaticano II, "La conciencia es el núcleo más secreto y el sagrario del hombre, en el que éste se siente a solas con Dios, cuya voz resuena en el recinto más íntimo de aquélla. Es la conciencia la que de modo admirable da a conocer esa ley cuyo cumplimiento consiste en el amor de Dios y del prójimo. La fidelidad a esta conciencia une a los cristianos con los demás hombres para buscar la verdad y resolver con acierto los numerosos problemas morales que se presentan al individuo y a la sociedad. Cuanto mayor es el predominio de la recta conciencia, tanto mayor seguridad tienen las personas y las sociedades para apartarse del ciego capricho y para someterse a las normas objetivas 
-eran primos entre sí- pasaran por la vergüenza de engendrar iguanas" (CAS, pp. 23-24) $)^{3}$, fruto de sus relaciones incestuosas.

La muerte de Prudencio Aguilar por difundir el secreto a voces: de la no consumación del matrimonio Buendía, pesaba duramente sobre la conciencia de la pareja. El malestar por las apariciones lo explica José Arcadio Buendía de esta manera: "los muertos no salen (...) lo que pasa es que no podemos con el peso de la conciencia" (CAS, p. 27).

José Arcadio Buendía, con esa ligereza de sus 19 años, resolvió el primer problema con frases como esta: "Si has de parir iguanas, criaremos iguanas" (CAS, p.26). "No importa tener cochinitos, siempre que puedan hablar" (CAS, p. 27). Y las angustias de las apariciones del muerto las quiso liquidar con el éxodo obligado en busca de una nueva vida. Después de la fundación de Macondo el comportamiento José Arcadio Buendía fue, en verdad, un modo ideal de proceder que les trajo felicidad ${ }^{4}$. Gabriel García Márquez subraya el nuevo comportamiento diciendo, al empezar la obra:

José Arcadio Buendía era una especie de patriarca juvenil, que daba instrucciones para la siembra y consejos para la crianza de los niños y animales, y colaboraba con todos, aun en el trabajo físico, para la buena marcha de la comunidad. (...) La laboriosidad de Úrsula andaba a la par con su marido. Activa, menuda, severa, aquella mujer de nervios imperturbables (...) parecía estar en todas partes desde el amanecer hasta bien entrada la noche (...). En pocos años, Macondo fue una aldea más ordenada y laboriosa que cualquiera de las conocidas hasta entonces (...). Era en verdad una aldea feliz. (CAS, p. 14)

de la moralidad. No rara vez, sin embargo, ocurre que yerra la conciencia por ignorancia invencible, sin que ello suponga la pérdida de su dignidad" (Constituciones, Gaudium et Spes, n. 16).

3 Las referencias a Cien años de soledad serán indicadas con la abreviatura $C A S$, seguida del número de página correspondiente a la edición de 1982 de Editorial La Oveja Negra Ltda.

4 La felicidad del hombre justifica el trabajo y el progreso: se supone que el hombre está sobre la tierra para alcanzar un grado cada vez mayor de felicidad y esa referencia al futuro hace al hombre necesitado de tiempo, de continuidad y de compromiso con las generaciones futuras. La vida feliz de los comienzos de la humanidad (paraíso) se ve favorecida por los descubrimientos y el trabajo: el fuego, el arado, la rueda, la comunicación, el arte, la navegación, el correo, el teléfono, la fotografía, el cine, etc. La organización social, jurídica y religiosa, han sido líneas universales de desarrollo y constitutivos de la cultura de los pueblos. 
Pero,

Aquel espíritu de iniciativa social desapareció en poco tiempo, arrastrado por la fiebre de los imanes, los cálculos astronómicos, los sueños de transmutación y ansias de conocer las maravillas del mundo. De emprendedor y limpio, José Arcadio Buendía se convirtió en un hombre de aspecto holgazán, descuidado en el vestir. (CAS, p. 15)

Como consecuencia del progreso, dicho cambio en la conducta de José Arcadio Buendía se hace notorio. El primer efecto del impacto es "el abandono por completo de sus obligaciones" (CAS, p. 10) y el descuido en la educación de los hijos, como lo indica Úrsula: "En vez de andar pensando en tus alocadas novelerías debes ocuparte en tus hijos -replicó [a José Arcadio Buendía]-. Míralos cómo están abandonados a la buena de Dios, igual que los burros” (CAS, p. 19).

Con la novedad de los inventos y el impacto del progreso en la familia, Macondo recibe un grave detrimento de la unidad familiar y de la educación de los hijos. Hay una lucha entre los esposos, una dedicación desmedida a la ciencia, a la industria y al comercio; la dispersión y las ausencias se multiplican por causa de las relaciones sexuales indebidas de los hijos y de sus inesperadas consecuencias. José Arcadio Buendía permaneció ajeno a la existencia de sus hijos, pues consideraba su infancia como un período de insuficiencia mental y, además, afirmaba que los errores en educación se remontan a los antepasados (CAS, p. 25).

Este es el punto de arranque del deterioro de la conducta de la familia Buendía; y su evolución hasta la desaparición de Macondo, borrado por un viento bíblico, es el contenido de nuestra investigación, la cual parte de la siguiente hipótesis: "Cien años de soledad es un planteamiento ético"' , que se justifica ampliamente por el estudio previo que hemos presentado en nuestra primera entrega ${ }^{6}$.

5 La ética se juega no en las posibilidades, sino en los hechos humanos: lo posible es dado al hombre para realizarlo de una manera u otra, con libertad, no a través de un destino que se impone. Por esa razón el hombre es capaz del bien y el mal. Dentro de la obra se vive esta lucha humana(...) aunque la acción éticamente mala parece empujada por un fatal determinismo mítico... esta marca con que la familia Buendía está señalada, se explica por el sentido simbólico de la obra que refleja inexorablemente los hechos de la vida real que representa. El hombre imaginario obra bajo un determinismo, el de reflejar y significar al hombre real histórico a quien en última instancia juzga el autor con extrema severidad y les aplica un castigo ejemplar.

6 Véase: Herrera S.J., 2015, pp. 23 
2. Base filosófico-antropológica y lingüística del razonamiento ético

\subsection{LA LENGUA}

Los JUicios ÉTicos COHERENTES los encontramos en la sabiduría secular que se concentra en la lengua: la integración de lo antropológico y lo lingüístico con la fe, en cuanto son vías de acceso para llegar a descubrir la norma ética humano-cristiana, es un camino seguro de investigación.

\section{La lengua es sabiduria bumana}

UNA DE LAS EXPRESIONES QUE RECOGE esta sabiduría acumulada por los siglos en la historia es el lenguaje: antes de la pérdida de los valores morales, el hombre señalaba con el apelativo de "bueno" o de "malo" la acción, la conducta y el ser del hombre. El sentimiento no es calificado, pues el sentir, al ser espontáneo, no es bueno ni malo. Así, entonces, es posible calificar al acto de bueno o de malo, lo mismo que a su repetición, que se torna en buen o mal comportamiento. Finalmente, por los hechos, por las costumbres o por el ser, se le califica a un hombre o a una mujer de bueno(a) o malo(a). Por tanto, acto, comportamiento o costumbre (mos, moris) y ser, se califican moralmente.

\section{La lengua señala la dignidad de la persona}

CON PREEMINENCIA, EL IDIOMA SIGNA al ser humano sobre los otros seres: persona/cosa; alguien/algo; nadie/nada; quien/que, de modo que el hombre tiene carácter único, insustituible. En cada persona radica la valía del ser humano y en ella está en juego la calidad, no la cantidad. El ser humano es un valor absoluto, de manera que lo ético tiene sentido si se apoya en él, en cuanto ser ético, subjetivo y personal. Según Rahner, el ser humano es consciente y libremente se posee, objetivamente se refiere a sí mismo y, ontológicamente, no es medio sino fin. Su valor y su dignidad absolutos de persona espiritual y libre radican en que al salir de sí se refiere a personas y las cosas las refieren a él.

\subsection{LA DIGNIDAD HUMANA}

LA DIGNIDAD DE LA PERSONA HUMANA es el sustento para legitimar los valores éticos del hombre. Si reconocemos la dignidad del hombre y sus derechos, le damos un fundamento a la valoración de la conducta humana y, a la vez, anticipa- 
mos el fundamento en que se apoyan los derechos humanos, ante todo, el derecho a la vida. La dignidad humana es una verdad que no se pliega a la corrupción que desmoraliza y el grado de conciencia logrado por la humanidad a lo largo de los siglos, constituye el fundamento por excelencia de los valores éticos.

\subsection{EL HOMBRE COMO FUENTE ÉTICA}

Si el hombre es fUente De ÉtiCA, es bueno lo que lo hace más humano, y malo, lo que lo deshumaniza. Es intocable en su vida y en su derecho a vivir dignamente. Se puede estimar su valor ético en su valía óntica de ser hombre. El acto humano es posible calificarlo de bueno si obramos conforme a la razón, si nos humaniza y nos realiza. Si el acto se vuelve costumbre, o si el obrar continuo del hombre es reprensible o si es inherente el obrar así, a determinada persona se le califica de hombre malo o de mala mujer. Así, el lenguaje acumula la sabiduría humana como fuente de valor ético que se refiere a la naturaleza de la acción, al talante o carácter y al ser mismo del hombre.

La norma ética no puede ser una fórmula abstracta, sino que el valor de la persona concreta debe ser reconocido, en su formulación, en ese valor ético intangible que respeta los valores fundamentales del hombre. Por eso, toda falla ética se refiere a faltar al respeto a la vida, a la sangre, al sexo humano o la justicia debida al hombre como persona o como comunidad. Estos son los aspectos en los que nos proponemos ahondar.

Desde la perspectiva de la creación, Dios da sentido y fundamento a la autonomía humana: la teonomía no suprime ni contradice la autonomía; por el contrario, es el fundamento válido que posibilita la autonomía. Como afirma Fuchs (1960), el hombre hecho a semejanza de Dios cimenta la moral teónoma, y la determinación material del bien proviene del hombre, del universo, de las cosas y de los objetos. Así, pues, la razón ética y el orden humano son normativos, consistentes y autónomos.

El hombre imaginario de las novelas, sus actos, sus relaciones, su libertad o la falta de ella, son significantes de la realidad humana con que se expresan sueños, ideales, condiciones sociales y concepciones de vida. Los personajes de Cien años de soledad nos revelan de modo fidedigno lo que significa ser hombre caribe, colombiano o latinoamericano. En el hombre imaginario aparece toda la carga ética de su comportamiento. Allí está su lucha: siguen o se separan de los principios o 
de los valores que constituyen lo humano. Se percibe la lucha universal del bien y el mal en que se inscribe la vida del hombre, lo mismo que el destino de Macondo.

García Márquez crea un mundo imaginario donde los personajes, en sus comportamientos, están marcados por un signo mítico-trágico que se evidencia desde el éxodo de su tierra, en busca de un paraíso de inocencia, hasta el impacto -especie de plaga- que les causa el progreso. El desaforado deseo de conocimientos los lleva al olvido de sus obligaciones, al descuido en la educación de sus hijos y al desbordamiento de los instintos y a la dispersión de la familia, con sus funestas e inesperadas consecuencias.

\section{Los factores determinantes}

Los factores determinantes del deterioro son: desarrollo de Macondo, educación y peste del insomnio. Nos dedicaremos a ellos en este apartado.

\subsection{EL DESARRollo de MACONDO}

EL PROGRESO QUE Llega A MACONDO es un tránsito de la etapa mítica primitiva a otra preindustrial, donde se hacen presentes nuevos elementos: conocimientos, inventos, avances, técnica y ciencias de carácter social, comercial, agrícola y de comunicaciones que no necesariamente están marcados por un sentido moral de mejoramiento humano, sino, más bien, por un progreso temporal de incremento y acumulación. Esto muestra que cuando el hombre, en su debilidad, se siente liberado por un nuevo tipo de sociedad y una nueva conducta que paulatinamente pierde el sentido de los valores ancestrales que estuvieron vigentes en sus inicios, reincide en sus mismos errores.

José Arcadio Buendía con su "imaginación desaforada" iba más allá del milagro y de la magia. El avance socioeconómico de modernización, producido por los conocimientos no bien asimilados del imán, la lupa, el daguerrotipo, el hielo, el teléfono, el cine, la música, la cultura artesanal de la confitería, platería, relojería y cultivo del banano, trajo la desgracia y desató el derroche, las pasiones y la corrupción, y engendró la huelga, la violencia y la muerte. En verdad, en Macondo, como en cualquier parte del mundo, la técnica sin ciencia y la ciencia sin conciencia son una nueva manera de barbarie. La politiquería estúpida y superficial engendra el 
fraude, la guerra y una falsa religiosidad anclada en la magia o en la ignorancia, que no dan respuesta a los problemas que sobrevienen a Macondo.

Macondo abandona su primitiva fisonomía tradicional agrícola para apropiarse de los avances foráneos en ciencias y técnicas, el uso de inventos modernos y el comercio, que lo invaden con una rapidez desorbitante y le arrebatan la tranquilidad y la paz de sus inicios.

\subsection{LA EDUCACIÓN EN MACONDO}

BAJO LA INSPIRACIÓN DEL PATRIARCA JUVENIL que impartía instrucciones a los niños (CAS, p. 14), la educación en la familia Buendía es, al comienzo, paradisíaca. Luego, la vida se abre en todas las direcciones al encuentro y a la relación con los otros, en un medio equilibrado y justo. La capacidad personal se despliega en relaciones humanas, bajo el liderazgo de José Arcadio y Úrsula, y en un espíritu de servicio que lleva a los personajes a identificarse y realizarse; esto es, a saber quiénes son y a desplegarse en todas sus dimensiones y potencialidades. De este modo, el ser humano representado por 'Gabo' sigue su destino hacia un bien supremo, pues está correctamente orientado en busca de horizontes más amplios (desarrollo) y hacia la conquista de bienes mayores (progreso), a través de las propias apetencias que, dramáticamente, nunca se pueden saciar aquí y ahora.

Si has de volverte loco, vuélvete tú solo", gritó [Úrsula]. "Pero no trates de inculcar a los niños tus ideas de gitano". (...) En vez de andar pensando en tus alocadas novelerías, debes ocuparte de tus hijos -replicó-. Míralos cómo están, abandonados a la buena de Dios, igual que los burros. (...) Mientras Úrsula seguía barriendo la casa que ahora estaba segura de no abandonar en el resto de su vida, él (José Arcadio) permaneció contemplando a los niños con mirada absorta, hasta que los ojos se le humedecieron y los secó con el dorso de la mano y exhaló un hondo suspiro de resignación. (CAS, p. 19)

En Macondo descubrimos que quieren saciarse aquí y ahora los más alocados impulsos. Este impacto los desvía de la felicidad de los inicios hacia la desgracia de una "hojarasca" de corrupción, de irrespeto a la vida, de irrespeto a la sangre y, desde allí, a los mayores exabruptos de violencia contra la justicia: guerra, explotación y despilfarro hasta llegar a un final catastrófico. Las lágrimas de los Buendía, dice Bollentino (1985) en un pequeño ensayo, no brotan por no 
poder abandonar a Macondo, sino por sentirse culpables de la vida que les queda en un mundo agobiado por "el sofocante olor a sangre". El hombre imaginario y su falta de ética producen un mundo infeliz de pasión y esclavitud que crea soledad y daña progresivamente la felicidad inicial y los valores atávicos.

La imaginación, los inventos y la novedad fascinan a los macondinos, los desequilibra, e inducen un cambio de costumbres que les arrebata la paz. De la aldea feliz pasan a la fiebre del progreso. Los estímulos que Macondo recibe de los gitanos, de la presencia del mago Melquíades y de todos los contactos que llegan de fuera, crean una bonanza con efectos deletéreos. La tradición y las virtudes ancestrales son suplantadas casi totalmente por las costumbres foráneas, lo que desata una lucha entre lo nuevo y lo viejo, entre lo extraño y lo autóctono, entre los antiguos moradores y la avalancha de los recién llegados.

El desarrollo industrial y científico, lo mismo que el de las comunicaciones, creó, con la llegada de la trasnacional bananera, una ambigua situación de bonanza que el autor llama "hojarasca" de injusticia, vicios, despilfarro y corrupción, y que muy pronto degeneró en total decadencia, después de un legendario diluvio, hasta que sobreviene un derrumbamiento definitivo. En palabras de García Márquez en La Hojarasca (1979, p. 39): "Es como si Dios hubiera declarado innecesario a Macondo y lo hubiera echado al rincón donde están los pueblos que han dejado de prestar servicio a la creación".

Son esas las razones del fracaso de Macondo, y Úrsula, la mujer que construye y conserva, que da vida y defiende la dignidad de la estirpe, y que trasciende la obra toda, las señala con luminosa precisión cuando desea que en Macondo no se hable sobre temas que han llevado la ruina a la familia:

- La guerra: interminable, cruel e inútil.

- Las riñas de gallos: símbolo de las luchas políticas.

- Las malas mujeres: irrespeto a la sangre, exageración en el sexo; también la presencia de la mala mujer, Pilar Ternera, que condesciende y relaja, que educa a su manera el ímpetu sexual de los Buendía y resuelve sus problemas con burdeles y asesorías celestinescas hasta instalar zooburdeles en Macondo conque culmina la corrupción sexual de los macondianos.

- La corrupción politiquera, las malas administraciones y el despilfarro en empresas delirantes. 
Estas son las verdaderas causas del derrumbe moral y de la desaparición física de la familia. ¡Solo una fuerza moral como la de Úrsula podría haber logrado un verdadero cambio! Pero no fue escuchada.

\subsection{LA PESTE DEL INSOMNIO Y DEL OLVIDO}

La PeSTe del insomnio llegó a Macondo desde Fuera. Los niños fueron abandonados en manos extrañas.

La peste del insomnio y del olvido no es una enfermedad que ataque al cuerpo, sino al espíritu. "Lo más terrible del insomnio es el olvido". El olvido del nombre de las cosas que se va agravando más y más. El no recordar afecta la mente y el corazón, el pasado y el futuro. Es algo misterioso y definitivo "que llevó a la deriva” a los habitantes de Macondo: jolvido de los valores, olvido de sí, ¡hasta la locura en el olvido de Dios! Es una confusión de sentidos que llevan al hombre al sinsentido de la vida.

De los Buendía se extendió al pueblo a través de los caramelos de Úrsula. Como la palabra, la peste era transmisible por la boca. Como en una nueva Babel, la peste amenazaba caer en confusión y en pérdida total de comunicación y de dispersión. Fue necesario escribir no solo el nombre de las cosas, sino su uso, pues el mayor miedo era olvidar "los valores de la letra escrita". Cuando el pasado perdiera su sentido para los tocados por la peste, habrían destruido el valor inapreciable de la cultura. Al olvidarse el hombre de sí, daría un último paso hacia el olvido de Dios y, al perderse la memoria de Dios, llegaría el hombre a la idiotez y a la locura, a una situación casi animal como para morir atado a un árbol, como fue la suerte del primero de la familia: José Arcadio Buendía.

Había hecho el esfuerzo de obtener la imagen de Dios por caminos equivocados, por ejemplo cuando creyó que el daguerrotipo pondría término a su ansiedad sobre la existencia de Dios y que, en caso contrario, acabaría de una vez por todas con la suposición de su existencia. Esto sucedió en el tiempo feliz de los inicios cuando la fundación de Macondo instauró un paraíso anterior a la historia y a la muerte, tiempo mítico, fundacional, primitivo y mágico. Una arcadia feliz trastornada por influjos foráneos de progreso y culturas venidas de fuera y no bien asimiladas. El impacto de la venida de los gitanos, de los avances de la ciencia y de los inventos, y las ansias de conocer, desconectan de la realidad y 
llevan al abandono y a la locura a los habitantes de Macondo. Además, la mala formación de los hijos en manos extrañas, contagia y multiplica el mal.

Superada la peste, viene un segundo tiempo en que Macondo entra a la modernidad de la ciencia, el comercio, la industria y las instituciones que contradicen, muchas de ellas, los valores propios de la población.

La avidez de conocimientos llevó a Macondo al deterioro de los comportamientos, a la fuga de las obligaciones, al abandono de los niños y al desvío de las buenas costumbres. En Macondo se recibió el progreso como un verdadero avance, como fruto del conocimiento científico y de los inventos: el imán, la lupa, el daguerrotipo y, más tarde, el hielo, el tren y los cultivos técnicos de la tierra y su explotación, que se tornaron ambivalentes y trajeron ambición, explotación, egoísmo, pasión y, sobre todo, olvido de los valores espirituales. Por ejemplo, el imán despertó la ambición por el oro, y la lupa, la ilusión del dominio en las guerras, lo que provocó el declive de la unidad familiar, ya que se pensó que era más importante aplicar el imán para enriquecerse, la lupa para quemar las embarcaciones enemigas o el daguerrotipo para hallar la imagen de Dios, que sacar a los hijos de la "vida de burros" que llevaban, solos y "abandonados de la mano de Dios".

Finalmente, a este desarrollo técnico-científico no correspondió un desarrollo ético y moral; esto es, un desarrollo humano espiritual equilibrante que orientara los adelantos materiales. Las fuerzas constructivas y liberadoras se tornaron en destructivas y esclavizantes y, en lugar de hacer felices y solidarios a los macondinos, se volvieron infelices, machistas, esclavos, prepotentes, altamente pasionales y solitarios.

Con todo, queda sin resolver este incisivo interrogante: ¿no bastan la técnica y la novedad de los inventos para elevar la calidad de la vida? No se puede dudar que el conocimiento, la técnica y la ciencia traen desarrollo a Macondo, pues sus habitantes se adentran en el saber sobre el mundo, aunque esto no garantiza el correcto comportamiento humano. Con el cambio de la vida patriarcal a la época preindustrial, identificada con la llegada de los gitanos y del mago Melquíades, quienes trajeron los adelantos de la ciencia, los macondinos pasaron del equilibrio, de la felicidad, de la justicia, de la juventud y del orden, al imperio del machismo y de la violencia sexual que los llevó a la infelicidad y a la soledad. De este modo, lo único claro es que los Buendía perdieron el rumbo de sus vidas, no 
respondieron a su destino posible y abandonaron a los niños en manos inadecuadas para su educación.

\section{Recapitulación}

EN EL ANÁLISIS ÉTICo que hemos desplegado sobre Cien años de soledad, hemos llegado hasta el momento a las siguientes ideas: uno, en realidad la obra de 'Gabo' es un clamor en favor de una ética global que responde a la dignidad de la vida humana integral; dos, al leer la obra surge en el lector una conciencia con respecto a la conducta ética de los personajes, pues el castigo final ilumina que:

1. Ante el irrespeto a la vida, se exige una ética de la vida.

2. Ante el irrespeto a la sangre, surge un clamor por una ética del sexo, del amor y de la familia.

3. Ante el irrespeto a la justicia, se escucha un gigantesco clamor por una ética social.

Estos tres puntos son un compromiso del lector ante el castigo final de Macondo: la explicación del castigo bíblico que borra para siempre a la familia Buendía y a los hijos de Macondo y les cierra la posibilidad de una segunda oportunidad sobre la tierra. El autor, con su "silencio" ético, nos permite entender que el fin trágico con que culmina la obra se debe a los malos comportamientos, por lo que el silencio de 'Gabo' nos da la libertad para que nosotros explicitemos a partir de los acontecimientos nuestro propio juicio ético.

No obstante, esos clamores a favor de la ética son explícitos en los personajes al iniciar la novela. De un lado, Úrsula representa la conciencia vigilante a lo largo de sus cien años de vida y su asombrosa claridad señala las guerras, las riñas y las malas mujeres, lo mismo que el despilfarro en las malas administraciones, como las causantes de la decadencia de los Buendía.

De otro, si recorremos rápidamente la obra de Gabriel García Márquez y catalogamos los atropellos que los hijos de Macondo hacen a la vida, encontramos una lista de homicidios, masacres, guerras, suicidios, genocidios y violencia que se podrían ordenar en una interminable sucesión de transgresiones e irrespetos al don más grande que Dios ha hecho al hombre: la vida. Como símbolo, queda 
por el suelo no solo un ferrocarril lleno de muertos, sino arlequines, reinas y payasos que colman la plaza después de la masacre.

Si tomamos los hechos que indican el irrespeto a la propia sangre: el sexo -que aparece no solo como exuberancia de vida, sino como exageración-, la prostitución, el zooburdel, la corrupción de menores, la doble moral matrimonial, las desviaciones hacia una vocación incestuosa de los Buendía y hasta el incesto, cabe preguntarnos: ¿No son estos los pecados característicos que ofenden a la dignidad del hombre y de la mujer? En el lapso de cien años se realiza una especie de metamorfosis en la que se pasa del paraíso y del orden al instinto de la animalidad y al desorden que culmina con el nacimiento de un niño con cola puerco. Por ello, se siente la necesidad de una ética del amor, de la sexualidad, de la familia, del respeto a la vida y de la justicia social, pues en este recorrido no podemos olvidar el otro aspecto arrollador de desigualdad y explotación que clama por la ética social: la guerra civil. Así, la presencia de la injusticia es clara. Se manifiesta en las huelgas, la opresión, la represión sangrienta, el fraude, el abuso de poder, la guerra, la politiquería, el despilfarro y la tiranía cruel e irresponsable de quienes parecía reivindicaban la revolución.

Lo anterior muestra el reflejo de un país que se manifiesta como uno de los más violentos del mundo, en donde la explotación de las transnacionales, la corrupción y las dependencias no dejan de engendrarse. Se trata, en últimas, del símbolo del continente latinoamericano, largamente explotado por un capitalismo salvaje y cruel.

En este símbolo, la presencia del mal y de lo feo puede tener justificación estética en la obra literaria total, pero no por el objeto representado, sino por el modo de representarlo y por el contraste y el efecto en la significación total de la obra. Depende, pues, del sentido total de la obra que, a mi parecer, es el paso, en una metamorfosis kafkiana, del hombre al animal, del incesto al insecto, que llega hasta el nacimiento del niño con cola de puerco que acabará comido por las hormigas. Esta lucha se prolonga hacia el porvenir, cuando otros "animales futuros arrebatarán a los insectos, el paraíso de miseria que los insectos estaban acabando de arrebatarle a los hombres" (CAS, p. 398).

A este respecto, es necesario distinguir entre sentimientos estéticos y juicios morales sobre lo bueno y lo malo. Una cosa es que el artista perciba el bien y el mal en su experiencia real o imaginaria y lo exprese de manera espontánea e intuitiva. 
Hasta ese momento su representación escapa al ámbito objetivo de la moralidad, ya que en lo estético se pueden desquiciar los valores literarios. Otra cosa distinta es cuando actúa la intencionalidad del sujeto, en cuanto al uso o al efecto que intente producir con tales imágenes. Sobre la intencionalidad no se puede juzgar; sin embargo, allí nuestra reflexión se encuentra de lleno en el área de lo ético.

No podemos negar que en García Márquez hay un trasfondo cristiano de creyente que emerge de su propio pueblo, de su propia cultura y de una infancia influida por el cristianismo en la que su abuela, su familia y su educación han sido un influjo determinante. Esta vinculación es francamente reconocida por el autor. Tampoco se puede negar una relación entre el mundo de Gabriel García Márquez y la revelación judeocristiana, puesto que en su obra encontramos muchos de los mitos: el paraíso, el pecado de origen, el temor a las consecuencias del pecado, el diluvio, la génesis de un pueblo y su desarrollo, y el éxodo, explícito cuando afirma que iban hacia una tierra "que nadie les había prometido".

Consideremos que también la historia, los signos de los tiempos y la literatura son lugares de revelación. La imaginación crea lugares en que Dios se puede manifestar positiva o negativamente. En los libros de la Sagrada Escritura no siempre Dios se manifiesta en el mundo positivo. Hay hechos negativos: la esclavitud, la muerte del inocente, el adulterio, la prostitución, y Dios se manifiesta en ellos, no solo a través de lo bueno, sino también a través de lo malo.

Y, aun suponiendo que Gabriel García Márquez no fuera creyente, como él mismo se confiesa, nos preguntaríamos: ecómo enjuiciar a un autor no creyente desde la fe? El autor nos podría decir que no ha construido su mundo desde la fe, sino desde la razón o desde la fantasía y la imaginación, aun con riesgo de fallar literariamente. Con ello, aunque estemos en un mundo imaginario, ¿serían aplicables unas claves de interpretación que no corresponden a la índole del mundo imaginario? Desde la cultura secularizada esto se rechazaría, pero si partimos del hombre como medida de todas las cosas, tendríamos que investigar en Cien años de soledad, su apertura como ser en el mundo, cuáles son sus ideales y sus utopías, y cuáles son sus ideas como incentivo de desarrollo y realización personal, ese mismo desarrollo que 'Gabo' cuestiona tan duramente, dentro del universo de Macondo, por sus terribles consecuencias. Así pues, vista desde fuera, la obra de Gabriel García Márquez narra las implicaciones de un pecado ancestral que la atraviesa toda; es más, en ella se puede juzgar la vida desordenada de los 
Buendía como un mal. Para ello, basta con una mirada que compruebe que en Cien años de soledad se reflejan los esquemas éticos que hemos estudiado.

\section{El planteamiento ético en Cien años de soledad}

LA OBRA DE GABRIEL GarCía MÁrQUEZ ostenta una gama de transgresiones humanas y el estrago que causa el comportamiento contrario a la ética en un pueblo: Macondo, en una familia: la Buendía, y en cada uno de los personajes. Así, el planteamiento ético que buscamos en el autor lo vislumbramos en el final de la obra, cuando los personajes son borrados por un viento bíblico y no se les da una segunda oportunidad sobre la tierra.

Este talante ético de la obra, tal como lo vimos arriba, se refiere al respeto a la vida, al amor, al sexo, a la mujer, a la familia y, finalmente, a los diversos aspectos de la justicia social. Sin embargo, las actuaciones del hombre imaginario corren el velo de una zona oculta y misteriosa del hombre, que es incomprensible e inexpresable: su pasión desbordada, expresión de un egoísmo que esclaviza. ¡Misterio de iniquidad!

Observamos en Macondo una doble moral: absoluta libertad sexual en el hombre y en la prostituta, en servicio del hombre. Exigencia de virginidad y de fidelidad en la mujer hasta el matrimonio o en caso de no casarse, hasta la muerte. Aun en las uniones libres, se exige fidelidad en la mujer. Relaciones incestuosas entre miembros de la familia hasta llegar al incesto que, cometido mentalmente o en la realidad, caracteriza a la familia Buendía y llega a ser temática de la obra. Los problemas del sexo llegan a convertirse en causa de homicidio por razón del honor como sucede con José Arcadio o con Fernanda del Carpio quien intenta matar a su nieto por ser hijo natural o el suicidio como manifestación de amores no alcanzados.

Para descubrir la concreción de normatividad ética de Macondo, basada en la moral cristiana, me apoyo en el sustrato católico de la cultura caribe que se manifiesta a través de Úrsula, quien actúa como sostén de los valores tradicionales, a la manera de las abuelas costeñas.

En el hombre imaginario, dentro de la novela, los actos de los personajes, sus relaciones, su libertad o su falta de ella, son significantes de la realidad humana con que se expresan sueños, ideales, condiciones sociales y concepciones de vida. Los 
actos nos revelan de modo fidedigno lo que significa el ser humano, ser hombre caribe, colombiano o latinoamericano. Allí aparece con toda la carga ética de su comportamiento: siguen o se separan de los principios o valores que constituyen lo humano. Se percibe la lucha universal del bien y el mal en que está inscrita la vida del hombre, lo mismo que el destino de Macondo.

Los hechos, por repetidos y comunes que aparezcan, no constituyen un valor ético, ni un criterio moral. La moral sociológica de las estadísticas no es la norma ética de los comportamientos humanos. La medida de todas las cosas es el hombre, su dignidad y su grandeza adquirida a lo largo del tiempo y expresada en hechos que lo dignifican y lo realizan.

"La sociedad con una ética pluralista pierde la valoración moral. Las tradiciones buenas entran a convivir con aquellas que las quieren derrumbar y se llega a una sociedad que no sabe distinguir el bien y el mal, y entran a regir morales contradictorias y ninguna establece primacía, y se llega hasta defenderse el derecho a la indignidad" (S.I.M.). Por eso nos preguntamos ¿̇cuál es la instancia normativa válida para el comportamiento moral del creyente? Es la razón humana iluminada por la revelación.

\subsection{EL IRRESPETO A LA VIDA: EL HOMICIDIO}

Intentemos deducir el Juicio ético que Gabriel García Márquez presumiblemente calla, pero que lo podemos encontrar en las luchas y acciones, en las actitudes y conductas de sus personajes en cuanto constituyen la vida y el destino de Macondo.

Nos hemos preguntado, ¿cuál es la instancia normativa válida para el comportamiento propio del creyente? (Suponemos que es la fe cristiana la que se refleja en Macondo, aunque a lo largo del tiempo vaya desapareciendo hasta la malicia del pecado mortal).

Para ser coherentes con lo dicho anteriormente, esa instancia es la razón, con su autonomía, y la revelación teónoma, las que evitan el formalismo y el legalismo del cristiano. La coherencia de los juicios morales la encontramos en la sabiduría popular que se concentra en la lengua misma: llama "bueno" y "malo" al hombre en su ser, en sus actos, en sus costumbres y se abstiene de calificar los sentimientos. 
En la integración de lo antropológico y lo lingüístico con la fe, en cuanto son vías de acceso y camino seguro, encontramos el justo medio para llegar a descubrir la norma de la conducta humano-cristiana.

La dignidad de la persona humana es el sustento para legitimar los valores éticos del hombre. Si reconocemos la dignidad del hombre y sus derechos, le damos un fundamento a la valoración de la conducta humana y anticipamos el fundamento en que se apoyan los derechos humanos, ante todo el derecho a la vida. El hombre es intocable en su vida. Es algo que no se pliega a la corrupción que desmoraliza: el grado de conciencia logrado por la humanidad en la historia a lo largo de los siglos constituye el fundamento por excelencia de los valores éticos.

Gabriel García Márquez crea un mundo nuevo que se explica por sí mismo: se trata de un cosmos, coherente, lanzado a nuestra capacidad de entenderlo unitariamente como una serie de acontecimientos que se clausura en 100 años.

Este mundo nuevo ha nacido de la obsesión de un pasado que zozobraba en la memoria de las gentes y que 'Gabo' rescata para la cultura: crea su mundo imaginario, crea un espacio, Macondo; crea unos personajes: la familia Buendía que se expande en sus intrincadas relaciones a lo largo de siete generaciones que sostienen la vida.

El borrar a Macondo de la faz de la tierra y no dar a sus habitantes una segunda oportunidad, el autor enjuicia duramente el mal comportamiento del hombre macondiano. Por lo que es claro que el planteamiento de Cien años de soledad es de tipo moral: desde el principio pesa sobre la familia Buendía, en primer lugar, la muerte de Prudencio Aguilar y, en segundo lugar, los enlaces matrimoniales entre primos, que se constituyen en un cargo de conciencia y se ven amenazados por una descendencia marcada como castigo. El complejo de Edipo, las relaciones incestuosas y el incesto cometido por Amaranta Úrsula, traerá inexorablemente el castigo temido: el nacimiento de un hijo con cola de cerdo, seguido de la destrucción de Macondo. Estos y los demás actos malos que aparecen continuamente en la obra son realidades que pesan en la decadencia, en el derrumbamiento de los valores y en la catástrofe final de Macondo. En la obra también es evidente que el miedo a los castigos es, en no pocos momentos, un motivo suficiente para realizar u omitir determinados actos, aunque semejante conducta no tiene nada que ver con la bondad moral. 
El autor nos revela, de la manera más cruda, lo que significa ser hombre. Los personajes se manifiestan con toda la carga ética de sus comportamientos, que siguen o se apartan de los principios y valores constitutivos de lo humano, en su sentido más profundo. En Cien años de soledad podemos hallar la lucha universal entre el bien y el mal, que se confunde con una conducta de vida muy latinoamericana, caribe y colombiana. En dicha tensión, el equilibrio está dado por las posibilidades del bien señaladas por Úrsula y por la maldad y su castigo, que devuelven las cosas al justo medio. Ahora bien, la razón, con su autonomía, y la revelación teónoma, son las instancias que evitan que el verdadero cristiano caiga en el formalismo y el legalismo. Con lo que la coherencia de los juicios morales la encontramos en la sabiduría popular que se concreta en la lengua misma que llama "bueno" o "malo" al hombre en su ser, en sus actos y en sus costumbres.

\subsection{EL IRRESPETO A LA SANGRE}

La DeCAdencia, el DeRrumbamiento de Macondo y el castigo final, son un juicio severo del autor al comportamiento del hombre macondiano. Es un juicio de totalidad que tiene un esquema bíblico, pecado/castigo, y que equivale a un juicio ético de estilo veterotestamentario.

En la reflexión sobre Cien años de soledad es notorio el movimiento ético de la obra, dentro del cual se desplaza el hombre de Macondo. Este movimiento se sustenta principalmente en la acción de tres mujeres: Úrsula, Pilar Ternera y Fernanda del Carpio. Si con estos personajes femeninos hacemos el esquema de cada uno de sus pasos y sus modos de proceder, encontraremos que la conducta de cada personaje está tomada de la obra, solamente hay que explicitar el juicio a que podemos llegar con la lectura total.

En la siguiente representación gráfica colocamos en letra distinta los textos, con los números entre paréntesis que señalan las páginas de la obra, donde aparece la confirmación de las hipótesis anteriores. En el esquema aparece Fernanda del Carpio entre la cerrazón y la ley, que son sus parámetros de acción, y Pilar Ternera, entre la apertura y la sociedad, que son los propios de este personaje. Entre los dos extremos aparece Úrsula Iguarán como expresión de la virtud y el equilibrio. Veamos: 


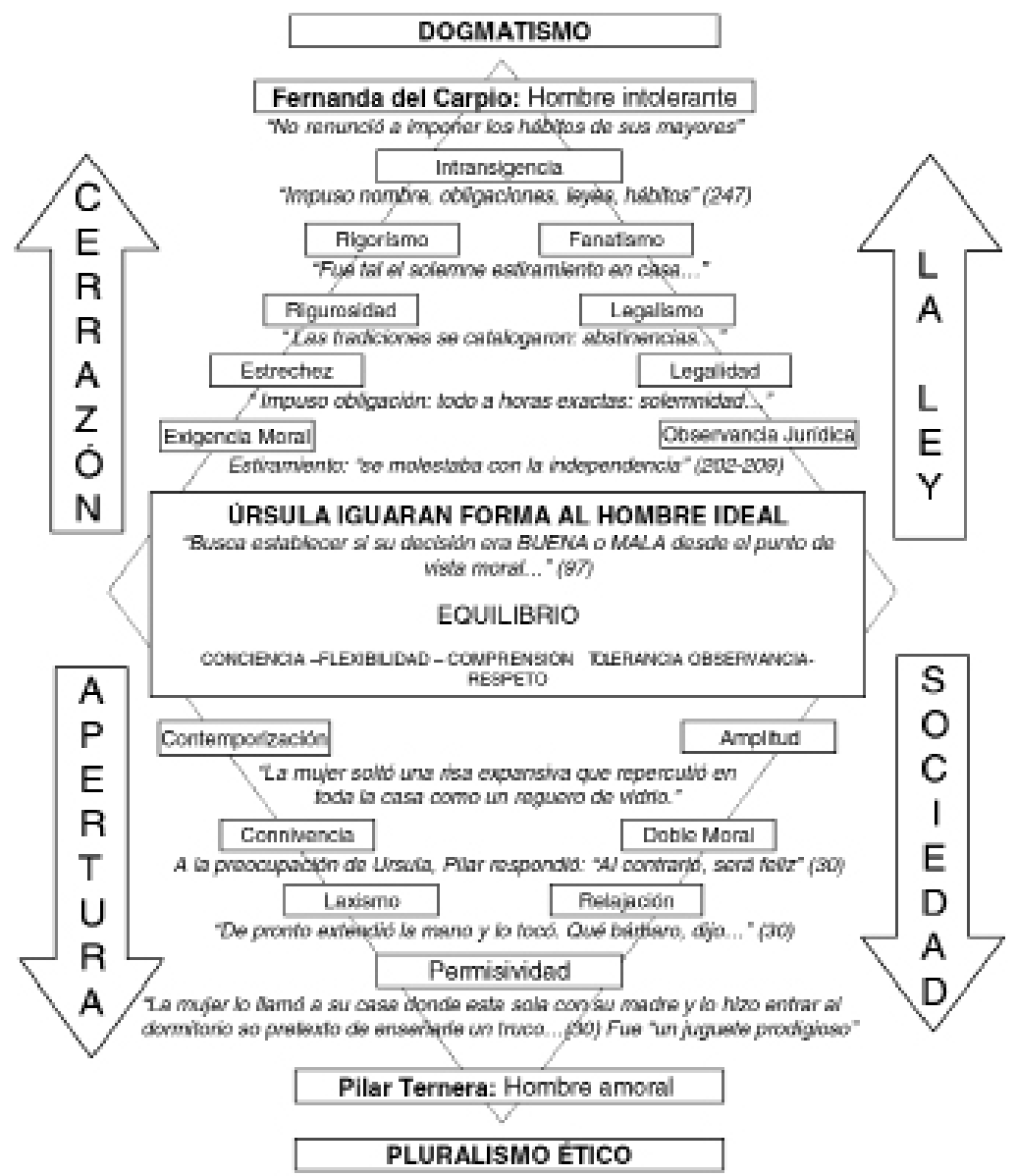

"Amparada por la impunidad del desorden colectivo (...) vivieron horas de desahogo" (CAS, p. 35)

\subsection{IRRESPETO A LA JUSTICIA}

ESTE ASPECTO ES LA CULMINACIÓN DEL ENJUICIAMIENTO del compromiso del autor con el hombre. En Macondo, desde la llegada de la multinacional bananera, la explotación del hombre desata las huelgas y su represión sangrienta. Al mismo tiempo, en la vida cotidiana aparece, unida al poder civil, la politiquería, el fraude y, como consecuencia, la guerra civil sin sentido, la tiranía de crueldad indecible y muchas muertes inútiles. 
Es indudable que los personajes obran así por la naturaleza del drama y por la conducta de los protagonistas. Justo en este sentido, la literatura es el espejo inexorable que refleja la realidad histórica.

Quizá sea razonable entender que los personajes imaginarios se convierten en metáfora o en símbolo de la realidad. Si nos introducimos con la ética de estos, encontramos a Úrsula que se erige en conciencia familiar, encargada de la lucha por la vida, por la educación y por la supervivencia de la especie, y cuyo juicio es certero con respecto a la decadencia moral de los Buendía. Pilar Ternera y Fernanda del Carpio, en cambio, permanecen como paradigmas de relajación y dogmatismo.

Úrsula sufre la irresponsabilidad y la seducción del negocio, pero lucha por la honestidad y la supervivencia de la estirpe. Al mismo tiempo, José Arcadio busca, en su locura, la imagen de Dios, y ante el fracaso de los medios inadecuados, deja de rastrearla "convencido de su inexistencia", con lo que pierde el sentido del tiempo y de su propia identidad. Este es el impacto que le produce el progreso y su ansia de ciencia, y con ello, pasando por la peste del insomnio y al olvido, la locura, hasta llegar al olvido de sí como consecuencia de su olvido de Dios que causa la destrucción de Macondo y de la familia Buendía, pues no tendrán una segunda oportunidad sobre la tierra.

Esta destrucción es el juicio del autor, quien borra su propia creación sin conceder a sus personajes una segunda oportunidad. Así, el enjuiciamiento recae en lo simbolizado y en todo comportamiento similar, lo cual es válido para todos los tiempos y lugares, pues tiene un valor mítico universal y es una intuición profética de un excelente escritor, a quien también, con razón, podemos llamar profeta de nuestro tiempo.

Por lo anterior, Germán Arciniegas concuerda con el juicio del autor, cuando dice: "Mirándonos en el espejo de Cien años de soledad, tenemos que enderezar la vida y responder por nuestro pasado macondino", cualquiera sea la ética que apliquemos.

\subsection{ENJUICIAMIENTO ÉTICO DE TOTALIDAD}

¿Cómo Se Produce el deterioro desde la ARCAdia feliz al infeliz Macondo? Todo era un paraíso de silencio anterior al pecado original (CAS, p. 17). La iniciación de la vida en Macondo se dio en un ambiente de convivencia, pues 
la paz social reinaba en la arcadia feliz (Arcadio). La aldea era modelo de una sociedad incipiente con un halo juvenil de inmortalidad, anterior al pecado, cuando el patriarca juvenil daba instrucciones para crianza de los niños (CAS, p. 14).

Después viene el impacto del progreso. Se despierta una avidez de ciencia y los inventos causan una revolución en las costumbres, lo que hace tránsito de la época patriarcal a la preindustrial. Llega la bonanza económica (Aurum: Aureliano). Hay una desaforada dedicación al estudio, a la creatividad y a la imaginación. Se configuran el comercio, el trabajo en plata y oro y el montaje de negocios que produce desasosiego y desconcierto. Empiezan a descontrolarse muchas cosas y se descuida la educación de los hijos, que son relegados a un nivel secundario. Como uno de los hechos importantes de los orígenes de Macondo, los niños y los adolescentes sufren las primeras consecuencias: la familia cambia de rumbo y los hijos se abandonan al olvido.

Prueba de ello es que Arcadio y A maranta aprenden guajiro antes que castellano y toman caldo de lagartija y huevos de arañas sin que Úrsula se diera cuenta $(C A S, \mathrm{p} .41)$. Al respecto Úrsula le reñía a José Arcadio con las siguientes palabras: "En vez de andar pensando en tus alocadas novelerías, debes ocuparte de tus hijos. Míralos cómo están abandonados a la buena de Dios igual que los burros" (CAS, p. 19). También, mientras Melquíades explicaba "las virtudes diabólicas del cinabrio, no le hizo caso, sino que se llevó a los niños a rezar" ( $C A S$, p. 14), y José Arcadio "permaneció ajeno a la existencia de sus hijos, pues consideraba su infancia como período de insuficiencia mental” (CAS, p. 20).

Otro de los impactos que sufre Macondo es la peste traída desde fuera por Rebeca y descubierta por Visitación, la india guajira, quien con su hermano huían del insomnio y en cuyas manos se relegó la educación de los niños. Cuando se acostumbraron al insomnio cayeron en el olvido. Se olvidaban del nombre de las cosas hasta tal punto que era necesario, para obviar las consecuencias de su olvido, roturarlas y señalar su utilidad. Fue menester poner un aviso en las afueras de Macondo que recordaba: ¡Dios existe!

Ahora bien, los errores en la educación sexual son ancestrales, empiezan desde la madre de Úrsula, quien por el temor de que le naciera descendencia con cola de puerco, como a sus antepasados, le fabrica a Úrsula un pantalón de castidad (CAS, p. 25). La incompetencia de la abuela en la educación la manifiesta también Úrsula con sus hijos adolescentes en pleno crecimiento. Así se ve cuando 
se afirma: "Aureliano era un adolescente monumental (...) Y estaba tan bien equipado para la vida que a Úrsula, su madre, le pareció anormal” (CAS, p. 28).

Creyó que era como la cola de puerco que temían para su descendencia (CAS, p. 29). Úrsula lo comentó a Pilar Ternera, quien le respondió: "Al contrario será feliz" (CAS, p. 30). Justo en este punto tenemos un largo proceso de iniciación en manos de una maestra, experta en permisividad y relajación. Ante esto, nos preguntamos: ¿con qué criterio juzgamos los desvíos del hombre imaginario, que simboliza y refleja al hombre real en su vida histórica, en un ambiente como el de la costa? ¡El hombre imaginario solo refleja necesariamente el ambiente!

En primer lugar, los personajes obran sin libertad, pues son reflejo de lo que pasa en la historia y están impulsados por el fatum, por lo que había sido escrito como destino con cien años de anticipación. Sin embargo, debemos aplicarles los criterios de una cultura católica que regía en el hombre histórico. ¿Cómo se entienden hoy estos criterios, aunque en Macondo estén desdibujados?

Con respecto a lo sexual, expongamos con claridad, siguiendo a Vidal (1990), estos criterios:

(1) El placer es bueno y sería infantil convertirlo en tabú, es algo positivo en sí, y aunque no es un valor absoluto, es constructivo; entre otros valores de la existencia humana, es un don de Dios entregado a la libertad del hombre y de la mujer en bien de la familia. El sexo lo entendemos referido a toda persona, hombre o mujer, y a sus manifestaciones.

(2) Lo sexual es una manera de ser permanente, y su ejercicio genital, una manera transitoria de manifestarse. Lo permanente es irrenunciable y consiste en poder experimentar deseo, atracción, enamoramiento, unión y placer (pathos). El hombre y la mujer están programados para experimentarlos y esa posibilidad no se puede valorar desde el (ethos) si no interviene la libertad de querer lo que espontáneamente se despierta.

(3) El ejercicio puede ser procreativo y en esto se despliega su valoración poderosa; es cocreador, en cuanto potencia: la respuesta humana es una secuencia ordenada, racional, de acontecimientos psicobiológicos "para" la reproducción de la especie, ciertamente no como "destino", sino abierta y posible en su orientación a otros fines, como la manifestación interpersonal y festiva del amor. Lo biológico es la raíz de la sexualidad humana. De ahí nacen las pulsiones del deseo, la atracción, el 
placer y la posibilidad de fecundidad. Hasta allí se extiende lo animal instintivo y se abre el hombre a otras dimensiones psicoafectivas, festivas y de satisfacción que se refieren a la identidad complementaria o recíproca, al modo peculiar de ser y de percibir la realidad. Se añade lo sociocultural que se ubica en un contexto de roles y relaciones interpersonales, y se incluyen la educación, la inserción en la cultura y la transmisión de estructuras jurídicas, políticas y sociales en que se vive.

(4) El hombre y la mujer reciben (pathos) y crean (ethos) su propio ambiente. En este contexto, la unión es manifestación de mutuo amor, pues el cuerpo humano es nupcial, capaz de descubrir la oblatividad que supone entrega libre y gratuita en la aceptación recíproca del otro, y en virtud de la masculinidad y la feminidad se convierten en donación creada para el amor (Juan Pablo II).

En Macondo se pasa de la época patriarcal del control a la permisividad, y al caer en ausencia de educación, en el instinto y en la pasión, se llega a la deshumanización y se desvirtualiza la sexualidad; esto es, se destituye de lo interpersonal y se convierte en egoísmo, sin autodominio ni racionalidad. Del instinto se pasa a la fuerza bruta y animal, que convierte a la mujer en máquina de placer, atropella su dignidad y hace del amor algo insignificante, exacerbado, absurdo y patológico.

Con frecuencia se manifiesta un erotismo orgiástico y vital que parece contrastar con la represión sexual de muchas regiones donde se guardan apariencias hipócritas. A veces se le da unas dimensiones cósmicas contra el decoro de las apariencias y el sexo se manifiesta con una potencia exagerada. Así, pues, el ámbito en que se mueve la ética del sexo la podemos clarificar con un esquema donde el rigor y la amplitud -permisividad- vienen temperadas con un concepto equilibrado, según la manera en que hemos considerado la ética. Veamos la siguiente gráfica sobre el comportamiento sexual humano: 


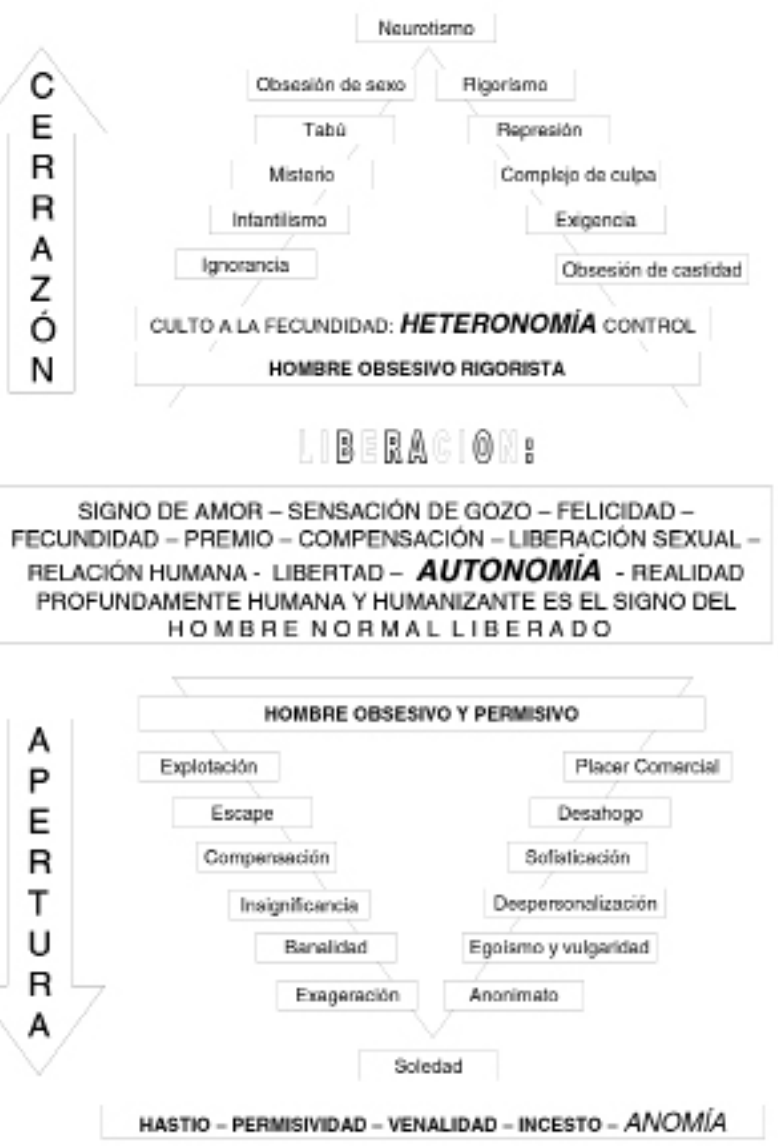

En Cien años de soledad, como en la vida humana, el sexo es un eje importante del comportamiento y en la obra de 'Gabo' se manifiesta con las características del medio: irrespeto a la sangre, a la familia y al sexo. Dichos irrespetos se pueden enunciar de la siguiente manera:

- La doble moral: absoluta libertad sexual en el hombre y en la mujer prostituta. Exigencia de virginidad en la mujer hasta el matrimonio o hasta la muerte. En las uniones libres se exige fidelidad.

- Relaciones incestuosas: el incesto se convierte en temática de la obra. 
- Causa el homicidio por honor, al ser tratado el hombre de impotente. Fernanda intenta ahogar al hijo natural de Meme, su nieto, para borrar la afrenta.

- José Arcadio en la tercera generación es sibarita y decadente, y se rodea de niños.

- Pilar abusa de los Buendía casi niños o adolescentes.

- El acto en la mujer es de pasividad, hasta el dolor insoportable, su virtud es resistir el goce mortal, sufrir sin queja. Consiste en la barbarie del descuartizamiento sadomasoquista. El hombre es sádico, masoquista, brutal, bárbaro y animal de poderes ciclónicos.

- En relación con sexo, hay una constante y significativa referencia al animal, sobre todo en la mujer: Ternera, es el apellido de Pilar. Gata (CAS, p. 112), perra (CAS, p. 24-342), comadreja (CAS, p. 334), caracoles, cangrejos (CAS, p. 326). Y el incesto produce o amenaza producir una descendencia animal (CAS, p. 249), cochinitos o iguanas, hasta que al final un niño nace con cola de cerdo. Es la metamorfosis anunciada a lo largo de la obra. El hombre responde al instinto (olfato): olorosa a animal crudo (CAS, p. 65), silbos de animal montuno (CAS, p. 325), aullidos de gata (CAS, p. 334). Es el camino de la decadencia o metamorfosis del hombre al animal, castigo del incesto, que tendrá su realidad en la cola de puerco del último de los hijos de Macondo.

Quizá Gabriel García Márquez pretenda derribar la hipocresía y llevar a los personajes hasta deshumanización del acto sexual, despojándolo de responsabilidades en los modos de proceder. Con frecuencia, no aparece la inteligencia ni la imaginación en los Buendía y se le quita al acto la dimensión festiva de comunión pues, a veces, la unión es bárbara, sádica, animal y convierte a la mujer en objeto de consumo, de explotación y pornografía; es reflejo del desenfreno histórico a que puede llegar el acto humano.

Con grave riesgo de comprometer la dignidad de la obra literaria, el autor se refiere a la historia real donde se banaliza el amor, uno de los aspectos más desarrollados en la obra que ha sido causa de censura en ciertas traducciones.

Por esta razón, el hombre imaginario devela zonas ocultas y misteriosas del corazón humano, evoca reliquias dormidas del psiquismo y, por medio del sím- 
bolo, se acerca al misterio del hombre, finalmente inefable, pues constituye "un misterio de iniquidad universal" que se hace indescifrable. Es posible que en su conjunto, el autor haga del mal su justificación estética como símbolo de una realidad que se desnuda, se descuartiza, dice 'Gabo', sin piedad y se desciende al subsuelo de los instintos.

Según la reflexión que hemos desplegado sobre este tema, sabemos que el hombre no solo es, sino que es digno. El hombre como ser personal tiene un valor infinito: hacia allá tiende la antropología cristiana en un nuevo concepto de persona. Solo así se puede plantear el proyecto ético de la historia y en esto consiste la originalidad del hombre. Hacerse persona es dar sentidos al individuo, ser de significados y valores absolutos, que reclama estima, realización, seguridad, vida y futuro.

En la creación, el hombre es la realidad más consistente: núcleo fontal del aprecio de toda otra realidad. En esto se funda la dignidad humana adquirida a lo largo de los siglos, de donde se deduce que es bueno lo que humaniza y malo lo que deshumaniza. De este modo, rescatamos al hombre como medida de todas las cosas. Solo en esta consideración adquiere dimensión universal una obra como Cien años de soledad. Esta es la culminación que daremos a nuestro trabajo, iniciado hipotéticamente como planteamiento ético en Cien años de soledad y con el propósito de probar que Gabriel García Márquez intenta en su obra un planteamiento ético.

\section{Epílogo}

Sinteticemos, para finalizar nUestra inVestigación, un estudio posible y posterior de las conductas éticas del hombre de Macondo. Estos comportamientos, en visión totalizante, serían acciones que se deben tener en cuenta, ordenadas así:

1. El homicidio, o irrespeto a la vida.

1.1 Muerte de Prudencio Aguilar.

1.2 Guerra civil, 32 levantamientos.

1.3 Matanza de las bananeras. 
1.4 Suicidio, violencia, tiranía cruel que levantan un clamor por ¡el respeto a la vida!

2. Las acciones contra el sexo, o irrespeto a la propia sangre.

2.1 Sexo: exuberancia de vida, abuso del sexo.

2.2 Vocación incestuosa: incesto.

2.3 Prostitución: Pilar Ternera.

2.4 Desviaciones: zooburdel. Corrupción infantil.

2.5 Doble moral: hombre/mujer, familia que exigen una ética del amor, de la sexualidad y la familia.

3. Los hechos de injusticia, o irrespeto a la justicia.

3.1 Clases sociales: desigualdad.

3.2 Derecho de huelga: represión.

3.3 Explotación de transnacionales: injusticia, dependencia y despilfarro.

3.4 Corrupción política, fraude y guerra.

3.5 Tiranía, abuso de poder que clama por una ética social.

Estos 3 numerales son, en conjunto, el vaivén de los movimientos éticos en la historia humana, desde la permisividad o pluralismo ético, hasta el dogmatismo que llega al fanatismo y tiene un valor universal.

El hombre de Macondo aparece crucificado entre la permisividad y la apertura de Pilar Ternera y la cerrazón de Fernanda del Carpio. Úrsula Iguarán es la norma de la conciencia moral que se erige como la línea media de la virtud. Es la horizontalidad de un esfuerzo fallido en la educación de su estirpe, ante la verticalidad de un rigorismo cuesta arriba, imposible, de Fernanda del Carpio y la permisividad, cuesta abajo, de Pilar Ternera, que prevalece con un éxito escandaloso, entre los hombres de la familia Buendía. Son líneas sostenidas y enfatizadas, por un matriarcado ético, que caracteriza las obras de García Márquez. En Cien años de soledad, Pilar es la relajación; Fernanda, la intransigencia y Úrsula, la conciencia moral, o el justo medio de la virtud que no siguieron los Buendía.

De este modo hemos llegado a la persuasión de que la obra maestra de Gabriel García Márquez, Cien años de soledad, es un verdadero planteamiento ético, con sabor de Antiguo Testamento: pecado/castigo. Es imperativo compararse con el planteamiento ético de la nueva alianza: pecado/perdón, distante de aquél, como 
del cielo a la tierra. Ante la visión desoladora del pecado del hombre, dijo Dios: "Hagamos redención del género humano" (Ejercicios espirituales de san Ignacio). Es decir: ¡Demos al hombre una segunda oportunidad sobre la tierra!

\section{Referencias}

Bollentino, V. (1985). De La Hojarasca a Cien años de soledad: Preparación de una novelística. Michigan: Michigan University.

Concilio Vaticano II. Constituciones. Gaudium et Spes. Disponible en línea: http:// www.vatican.va/archive/hist_councils/ii_vatican_council/documents/vat-ii_ decl_19651207_dignitatis-humanae_sp.html

Fuchs, J. (1960). Derecho natural. Ensayos teológicos. Turnai.

García Márquez, G. (1982). Cien años de soledad. Bogotá: Editorial La Oveja Negra Ltda.

García Márquez, G. (1979). La Hojarasca. Barcelona: Gráficas Guada, S.A.

Guariglia, O. (1992). Kantismo. V. Camps, O. Guariglia \& F. Salmerón. (Eds.), Concepciones de ética (pp. 53-72). Madrid: Editorial Trotta/CSIC.

Herrera S.J., L.C. (2015). Gabriel García Márquez y la ética en Cien años de soledad - I. Universitas Philosophica, 32(64), pp. 197-234 doi:10.11144/Javeriana.uph32-64.ggmc

Novoa S.J., C. (1995). El surgimiento histórico de Jesús según el espiritu: La formación de la conciencia moral. Bogotá: CEJA.

Novoa S.J., C. (2000). La relación entre la ética, la teología, la filosofía y la interdisciplinariedad científica. Theologica Xaveriana, 136, pp. 469-474.

Vidal, M. (1990). Moral de actitudes, moral fundamental, moral de la persona y bioética teológica, moral del amor y de la sexualidad, y moral social. Madrid: Ed. Covarrubias. 